\title{
Imaginários europeus no Brasil Imperial: uma análise da obra de Ida Pfeiffer
}

\author{
[The European imagery of imperial Brazil: an analysis of Ida Pfeiffer's work] \\ http://dx.doi.org/10.11606/1982-88372444124
}

\section{Gisele Eberspächer $^{1}$}

\begin{abstract}
Among the travels of the Austrian writer Ida Pfeiffer (1797-1858) was a two-monthlong stay in Rio de Janeiro in 1846. Her travelog (Eine Frau fährt um die Welt) on this experience, as well as the books of the same genre, contributes to the creation of the imaginary of Brazil among her European readers. But it could also be said that the book the author's imaginary of what she might encounter in Brazil, as well as those of other Europeans. This article presents the results of an analysis of the moments in the text in which these imaginaries are made evident by the author, the book being thus considered a historical source of the European imaginary about Brazil in the $19^{\text {th }}$ century.
\end{abstract}

Keywords: Travel literature; Ida Pfeiffer; The European imaginary of Brazil.

Resumo: Entre as viagens da escritora austríaca Ida Pfeiffer (1797-1858) esteve uma estadia de cerca de dois meses ao Rio de Janeiro, realizada em 1846. Seu relato dessa experiência no livro Eine Frau fährt um die Welt, assim como os outros livros do gênero, alimenta um imaginário sobre o Brasil entre seus leitores europeus. Mas, além disso, apresenta vários dos imaginários da autora e de seus conterrâneos acerca do que encontraria no país. O presente artigo busca realizar um levantamento dos trechos em que esses imaginários ficam explícitos no relato da autora, tomando sua obra como uma fonte histórica dos imaginários europeus do século XIX acerca do Brasil.

Palavras-chave: Literatura de viagem; Ida Pfeiffer; Imaginários europeus sobre o Brasil.

Era primavera e me sentei um dia para escrever a respeito do caminhar, mas logo me levantei de novo, porque a escrivaninha não é lugar para se pensar em grandes proporções.

Rebecca Solnit ${ }^{2}$

\footnotetext{
${ }^{1}$ Universidade Federal do Paraná, Rua General Carneiro, 460, Curitiba, PR, 80060-000, Brasil. E-mail: gisele.eberspacher@gmail.com. ORCID: 0000-0001-5195-980X

${ }^{2}$ Solnit (2016: 21).
}

\section{(cc) BY-NC}




\section{Introdução}

Em 1846, enquanto uma embarcação europeia, vinda de Hamburgo, se preparava para cruzar a linha do Equador em direção ao Hemisfério Sul, seus passageiros discutiam quais seriam as terríveis consequências do ato: do apodrecimento de todos os insumos a uma fadiga extrema por parte da população, todos tinham em mente alguma catástrofe. No fim, absolutamente nada acontece, e a viagem segue normalmente. Apesar do anticlímax, o episódio revela o quanto os europeus eram povoados por diversos imaginários sobre os lugares distantes, de situações extraordinárias aos formatos da vida cotidiana.

A cena faz parte do relato de viagem escrito pela austríaca Ida Pfeiffer em sua passagem pelo Brasil, uma narrativa repleta de indícios do imaginário europeu sobre o país. Uma vienense aventureira, Pfeiffer elegeu o país como primeira parada de sua primeira volta ao mundo, viagem iniciada em 1846. Os meses que passou no Brasil, além de narrarem eventos e situações sociais do país e constituírem um importante documento histórico do Brasil Imperial, mostram também as várias expectativas que ela tinha quanto ao país - e se elas se concretizaram ou não.

Para investigar um pouco desse imaginário - como mencionado por Pratt (2003) e Holanda (2000) - e como ele se apresenta no texto de Pfeiffer, proponho neste artigo uma análise dos capítulos iniciais do relato Eine Frau fährt um die Welt, nos quais a autora relata sua experiência brasileira, chamando atenção para os trechos em que a autora ressalta mais explicitamente o que era pensado e dito sobre o país em seu contexto cultural de origem, a Viena do período do Biedermeier. O objetivo, portanto, é identificar os trechos que explicitam esse imaginário, comentá-los à luz da experiência da autora e investigar os efeitos narrativos da presença dessa característica no texto. Para isso, em um primeiro momento cabe a contextualização da autora, cuja literatura é marcada pela sua própria movimentação e distanciamento do espaço de origem, para então seguir para a apresentação e análise dos trechos selecionados e suas implicações na narrativa de Pfeiffer.

A análise se baseará em Pratt (2003), Holanda (2000) e Süssekind (1990) e permite a observação do texto de Pfeiffer em sua relação etnocêntrica com o Brasil. 


\section{Ida Pfeiffer}

Ida Pfeiffer (1797-1858) foi uma escritora e viajante austríaca que publicou cinco relatos de viagem. É considerada a primeira autora em língua alemã a dar uma volta ao mundo, além de ser uma das poucas escritoras de seu tempo que tinha como objetivo de sua viagem a viagem em si, além do relato dessas experiências (HABINGER 2014 e SERRANO 2017).

Segundo a pesquisadora portuguesa Sónia Serrano, que em seu livro Mulheres Viajantes discorre sobre a história de várias viajantes, a infância de Ida Pfeiffer “decorreu num ambiente masculino; era uma maria-rapaz encorajada pelo pai a adotar comportamentos à época mais apropriados para os homens" (SERRANO 2017: 255). A morte do pai trouxe uma adolescência conturbada, repleta de atritos com a mãe que esperava um comportamento mais feminino, de acordo com os padrões da época, o que nem sempre correspondia às vontades da jovem. Em 1820, aos 22 anos, casou-se, por insistência e arranjo da mãe, com Mark Anton Pfeiffer, um advogado viúvo 24 anos mais velho do que ela e com uma posição importante no governo austríaco - o que garantiria, segundo a mãe, estabilidade na vida de Ida. Serrano (2017) relata, porém, que a realidade foi diferente: Mark Pfeiffer se viu em uma posição política delicada depois de ter denunciado um caso de corrupção pública e perdeu o emprego, levando a família a passar por profundas dificuldades financeiras. Ida começou a dar aulas de música para conseguir sustentar os filhos. A situação financeira complicada diminuiu com a morte da mãe de Ida, que lhe rendeu uma pequena herança com a qual consegue se fixar em Viena. Segundo a biógrafa de Pfeiffer, a pesquisadora austríaca Gabriele Habinger, o casal se separa informalmente em 1833: "Não era falado abertamente, mas claro que o casal seguia cada qual seu caminho"33 (HABINGER 2014: 26). O divórcio oficial não era uma opção na sociedade austríaca do período.

Ida Pfeiffer se viu livre para mudar de vida em 1842, aos 45 anos de idade, quando seus filhos já estavam crescidos e eram independentes. Pfeiffer retoma seu sonho de juventude: conhecer regiões distantes e costumes estranhos à cultura austríaca do período. Segundo Habinger (2014: 28), "Uma coisa é clara: ela viajaria sozinha. Seu marido de quase 70 anos de idade já era velho demais para acompanhá-la. E, provavelmente, depois

\footnotetext{
${ }^{3}$ No original: Es wurde zwar nicht offen ausgesprochen, doch die beiden Eheleute gingen nun getrennte Wege.
}

Pandaemonium, São Paulo, v. 24, n. 44, set.-dez. 2021, p. 124-140 
EBERSPÄCHER, G. - Imaginários europeus no Brasil Imperial

de quase uma década separados, ela também não gostaria de tê-lo ao seu lado"4 Depois de vender alguns poucos pertences e fazer um testamento, afinal viajar era uma ousadia tão grande que não acreditava que voltaria com vida, se pôs a viajar.

Pfeiffer realizou cinco grandes viagens entre 1842 e 1858, ano da sua morte, sendo que duas foram voltas ao mundo. Essas experiências de viagem foram a base para toda sua obra escrita. As narrativas de viagem, publicadas a partir de 1846, chegaram a se tornar best-sellers na Áustria do período (HABINGER 2014). O destino da primeira viagem de Pfeiffer foi o Oriente Médio e o norte da África, o que fazia com que a viagem parecesse uma peregrinação e lhe daria uma justificativa para viajar sozinha, algo incomum para mulheres da sua sociedade. Ela passou por cidades como Istambul, Jerusalém e Cairo, descreveu o Mar Morto e conheceu a Itália no caminho de volta. As memórias dessa primeira viagem lhe renderam a publicação do livro Reise einer Wienerin in das Heilige Land (Viagem de uma vienense à terra sagrada), publicado em 1843 (sem sua assinatura, diga-se de passagem. Seu nome só apareceria na quarta edição do livro, de 1846). A renda advinda da publicação dessa obra foi inclusive um dos fatores que permitiram suas viagens posteriores.

A partir disso, não nascia apenas uma viajante, mas também uma escritora. $\mathrm{O}$ segundo destino da autora foi o norte da Europa e o relato dessa experiência, intitulado Reise nach dem skandinavischen Norden und der Insel Island (Viagem ao Norte Escandinavo e à Islândia), foi publicado em 1846. Habinger (2014) relata que Pfeiffer foi, até onde se sabe, a primeira pessoa a fazer registros fotográficos da Islândia - chegou inclusive a fazer um curso para aprender a manusear corretamente os pesados e complexos daguerreótipos. A autora começa também a se aproximar de diversas Sociedades Geográficas da Europa, buscando entre elas uma forma de financiar suas viagens e de realizar seu sonho por meio de venda de amostras naturais e artefatos etnográficos. A participação das mulheres nesses ambientes científicos ainda não era amplamente permitida, mas vários espaços se mostraram dispostos a comprar itens que ela trouxesse de suas viagens, tais como pedras, sementes, flores, roupas, adereços, etc.

Depois do sucesso de suas duas primeiras viagens, Pfeiffer começa a planejar sua viagem mais ousada até então: uma volta ao mundo. $\mathrm{O}$ interesse pela escritora e suas viagens já é suficiente para que um registro de sua partida fosse feito em um jornal.

\footnotetext{
${ }^{4}$ No original: Eines ist klar: sie muss alleine reisen. Ihr Mann ist mit seinen fast siebzig Jahren zu alt, um sie zu begleiten. Wahrscheinlich hätte sie ihn, nachdem sie nun fast ein Jahrzehnt ohne ihn zurechtgekommen ist, gar nicht allzu gern an ihrer Seite gehabt.
}

Pandaemonium, São Paulo, v. 24, n. 44, set.-dez. 2021, p. 124-140 
EBERSPÄCHER, G. - Imaginários europeus no Brasil Imperial

Ludwig A. Frankl registrou no suplemento dominical „Sonntagsblättern für heimatliche Interesse" que a vienense partira com destino ao Brasil. Segundo Habinger (2014: 79), “O público austríaco podia, então, acompanhar nos jornais as viagens e experiências da conterrânea enquanto elas aconteciam", já que os jornais faziam atualizações frequentes de sua jornada. Após uma estadia de cerca de três meses no Brasil, Pfeiffer continuou sua viagem dando a volta pelo temido Cabo Horn, até chegar ao Chile e, então, à Ásia e ao Oriente Médio, de onde retornou para Viena, chegando em 1848. O livro Eine Fraue fährt um die Welt (Reise von Wien nach Brasilien, Chili, Otahaiti, China, Ost-Indien, Persien und Kleinasien) - A jornada de uma mulher pelo mundo (Viagem de Viena para o Brasil, Chile, Haiti, China, Índia, Pérsia e Ásia Menor) - seria publicado apenas em 1850, dois anos depois do seu retorno. É esta obra que o presente artigo comenta.

Sua próxima viagem também foi uma volta ao mundo - desta vez passando pela África, pelo Arquipélago Malaio, pelos Estados Unidos, pelo Peru e pelo Canadá, e lhe rendeu sua quarta publicação em 1856. Seu retorno a traz para uma situação diferente daquela da qual saiu, já que o sucesso do relato de sua primeira volta ao mundo encontrou muitos leitores e fez com que ela se tornasse uma figura conhecida. Pfeiffer recebeu prêmios, foi convidada para fazer parte de Sociedades Geográficas (como a de Berlim e a de Paris) e foi retratada em litografias. Ainda assim, Habinger (2014) afirma que Pfeiffer era criticada fortemente pela imprensa do seu país - seus apoiadores geralmente estavam em Londres ou Berlim.

A última viagem da austríaca começou em 1856 e tinha como primeira parada a ilha de Madagascar, sobre a qual pouco se sabia na Europa (HABINGER 2014). Com base nos relatos de Pfeiffer, essa foi a viagem mais atribulada da autora, por conta principalmente de conflitos políticos internacionais (França e Inglaterra brigavam pelo controle da ilha) e de revoltas nacionais. Além disso, problemas de saúde fizeram com que Pfeiffer acreditasse que morreria na ilha africana. Porém, a vienense conseguiu retornar para Áustria, onde encontra abrigo na casa de seu irmão, Carl, onde faleceu na madrugada entre os dias 27 e 28 de outubro de 1858. Seu último livro, Reise nach Madagaskar (Viagem a Madagascar), foi publicado postumamente por Oscar Pfeiffer, filho da autora.

\footnotetext{
${ }^{5}$ No original: Das österreichische Publikum kann darüber hinaus in den Zeitungen laufend die Reiseetappen und Erlebnisse der unerschrockenen Landsfrau mitverfolgen.
} 
EBERSPÄCHER, G. - Imaginários europeus no Brasil Imperial

Ida Pfeiffer não foi a primeira viajante a vir para o Brasil e deixar seu relato sobre o país, mas é, ao menos entre as autoras e relatos conhecidos, a primeira a vir para as terras brasileiras com nenhum objetivo além da viagem em si. Jemima Kindersley, Isabelle Odonais, Elizabeth Macquire e Rosa Freycinet são algumas das mulheres que vieram antes de Pfeiffer - as três vieram como acompanhantes de seus maridos ou estavam indo encontrá-los, além de terem frequentando círculos sociais muito específicos, formados principalmente por conterrâneos seus e outros nobres (FRANÇA 2008 e SerRANo 2017). Já a inglesa Maria Graham deixou um relato mais completo em forma de diário sobre um Brasil em transformação no período de sua independência, mas também veio ao país pela primeira vez para acompanhar o marido em viagem e uma segunda vez para trabalhar como tutora da família real. Como as outras autoras, também circulou por grupos mais específicos (GRAHAM 1824). Pfeiffer não só veio sozinha com o fim exclusivo de conhecer o país, como também é uma das autoras que circulou por espaços mais variados (de cidades a pequenas excursões pela natureza, chegou a visitar várias fazendas e até uma tribo indígena), o que faz com que sua obra se destaque nesse contexto de produção.

\section{A jornada de uma mulher ao redor do mundo}

Como dito, este artigo tem como objeto de análise os primeiros capítulos do livro Eine Fraue fährt um die Welt (Reise von Wien nach Brasilien, Chili, Otahaiti, China, OstIndien, Persien und Kleinasien), nos quais a autora relata sua experiência de viagem ao Brasil. Esse recorte da obra de Pfeiffer apresenta principalmente dois gêneros textuais: o formato de diário (usado principalmente para narrar os períodos de deslocamento da Europa ao Brasil, ou do Brasil para o Chile, assim como as pequenas excursões que fez para regiões mais afastadas do Rio de Janeiro durante sua estadia) e um gênero mais descritivo, mais semelhante a um texto jornalístico e até etnográfico, no qual deixa de se preocupar com datas específicas de determinados acontecimentos para descrever as cidades, os espaços e a sociedade e suas impressões sobre eles sem a discriminação explícita e frequente dos dias em que determinadas observações ocorreram (como pode ser visto no capítulo em que descreve a cidade do Rio de Janeiro). Ainda, pode-se observar a ocorrência de um terceiro gênero: entremeadas por estes dois momentos estão várias dicas de viagem, que se aproximam mais ao gênero atual de guias turísticos, com 
EBERSPÄCHER, G. - Imaginários europeus no Brasil Imperial

as quais ela faz recomendações práticas para futuros viajantes (desde itens importantes para se levar na bagagem aos preços de determinados serviços).

Esses momentos correspondem também a uma mudança em termos de narração: nos trechos em formato de diário, é comum que Pfeiffer adote a primeira pessoa do plural (se referindo aqui a um coletivo como "nós, os viajantes do barco"), enquanto os trechos mais descritivos têm uma narrativa mais focada em terceira pessoa do plural (em "eles, os brasileiros”) e, eventualmente, primeira pessoa do singular (ainda que Pfeiffer não descreva tanto assim indivíduos específicos). Nos dois momentos, se encontram trechos com primeira pessoa do singular, no qual a autora se distancia de um grupo ou emite uma opinião mais explicitamente pessoal sobre o que observa.

Importante ainda mencionar que a obra de Pfeiffer, mesmo em seus trechos mais descritivos, é subjetiva. Uma das marcas textuais disso é uso constante de expressões como "o que me chamou atenção", "me acostumei..." ou "foi muito interessante para mim", que registram fortemente as impressões de um "eu". A autora adota também um uso intenso de adjetivos e advérbios, raramente omitindo sua percepção dos lugares que a cercam. Seu texto é permeado por estruturas que mostram as experiências e opiniões da autora de forma pouco explícita, chegando em um estilo que optei por chamar de descrição subjetiva. Isso evidencia ainda mais um fator um tanto óbvio, mas nem sempre levado em consideração quando se lê um texto de cunho mais factual: o que o ponto de vista de Pfeiffer, enquanto mulher vinda de uma sociedade culturalmente dominante, perpassa sua experiência de percepção e descrição do mundo. O etnocentrismo é uma marca forte de todo o seu texto - e fica evidente quanto apresenta frequentemente em seu texto o imaginário austríaco e europeu em relação ao Brasil, tema aprofundado a seguir.

\section{Imaginário}

O Brasil e a América do Sul como um todo eram uma incógnita para os viajantes e os leitores europeus por muito tempo. Principalmente no período da União Ibérica (15801640), questões de política colonial proibiram a vinda de viajantes e pesquisadores para as colônias espanholas e portuguesas na América do Sul. Com isso, o continente era pouco conhecido pela maioria dos europeus.

Os relatos começam a surgir com mais frequência quando a política tão fechada começa a se flexibilizar - a corte espanhola, por exemplo, permite a vinda de Alexander 
EBERSPÄCHER, G. - Imaginários europeus no Brasil Imperial

von Humboldt para o então território espanhol na América do Sul em 1799 - a partir disso, a viagem e os relatos sobre o continente são fontes centrais para se entender a imagem da América do Sul para os europeus (PRATT 2003). Antes, sem fontes confiáveis de relatos sobre o continente, o espaço vazio era preenchido por narrativas muitas vezes imaginárias e até fantasiosas. Com a ascensão do Naturalismo, o aumento da frequência de viagens e a abertura de fronteiras, se abre a oportunidade para o desenvolvimento de um pensamento um pouco mais científico (PRATT 2003). E é justamente nesse contexto que se insere Pfeiffer - um momento que já vê uma demanda maior por relatos mais factuais e menos fantasiosos, mas que ainda são permeados pelos imaginários construídos pelas narrativas anteriores.

Nos capítulos do livro Eine Frau fährt um die Welt dedicados aos dois meses em que passou no Rio de Janeiro, a autora compartilha suas impressões sobre a sociedade e a natureza brasileiras. Além disso, em vários momentos explicita qual era sua expectativa e fornece outros dados ou informações que soube sobre o Brasil antes de sua visita ao país, muitas vezes contrastando a expectativa com a realidade. Esses trechos mostram o que Pfeiffer, uma autora importante do período quando se pensa na construção do imaginário europeu sobre países distantes, conhecia do Brasil antes de visitá-lo. Conhecimento este que contém elementos do que se imaginava do país na Áustria. Assim, destacar e refletir sobre esses trechos nos dão acesso ao imaginário europeu do século XIX sobre a vida e os costumes brasileiros.

Pfeiffer começa sua viagem a bordo de um veleiro que parte de Hamburgo em junho de 1846. A primeira menção às expectativas dela em relação à sua viagem é breve e indireta, mas indica o que esperava do clima quando o barco passa pela latitude do mediterrâneo e norte da África: "04 de agosto. Esse foi o primeiro dia no qual sentimos, pela temperatura, que estamos em uma latitude mais ao sul" (PFEIFFER 1850: 13 apud EBERSPÄCHER 2020: 120$)^{6}$ - ou seja, calor. Alguns parágrafos a seguir, a autora comenta sua ansiedade por observar o Cruzeiro do Sul - na expectativa de ver uma constelação não visível do hemisfério norte. Um relato mais detalhado das expectativas se apresenta quando o barco cruza a Linha do Equador, a cena descrita no começo do artigo:

No dia 29 de agosto, às $22 \mathrm{~h}$, saudamos o hemisfério sul! Um sentimento muito parecido com o orgulho percorreu a todos, principalmente aqueles que cruzavam a linha pela primeira vez. Nós apertamos as mãos uns dos outros e nos parabenizamos mutuamente, como se esse fosse um feito grande e heroico. Um dos passageiros trouxera consigo uma

\footnotetext{
${ }^{6}$ Aqui, assim como para todas as citações de Pfeiffer, adota-se a tradução de Eberspächer (2020), publicadas em sua dissertação de mestrado.
}

Pandaemonium, São Paulo, v. 24, n. 44, set.-dez. 2021, p. 124-140 
EBERSPÄCHER, G. - Imaginários europeus no Brasil Imperial

ou duas garrafas de champagne para comemorar o evento. As rolhas voaram alegremente pelo céu e, com desejos de vida longa, bebemos à saúde do novo hemisfério.

A tripulação não festejou. Era assim na maioria dos navios para que eventos como esse não terminassem em bebedeiras e desordens. Os marinheiros, porém, não deixaram passar em branco a primeira passagem para o hemisfério sul do aprendiz do navio, que foi batizado com vários baldes de água salgada.

Algum tempo antes de cruzar a linha, nós, os passageiros, conversávamos com frequência sobre os sofrimentos e torturas aos quais estaríamos sujeitos no Equador. Todos tinham lido ou ouvido coisas completamente horríveis e insistiam em contá-las para os outros. Um esperava sofrer dores de cabeça e cólicas; o segundo imaginava que os marinheiros cairiam de exaustão; um terceiro receava um calor tão intenso que não só derreteria o alcatrão, mas também secaria o navio, sendo que só jogar água continuamente na embarcação evitaria sua combustão; um quarto temia que as provisões estragassem e todos morressem de fome.

Quanto a mim, já me alegrava com as histórias trágicas que poderia apresentar para meus leitores; já os via vertendo lágrimas com as narrações dos nossos sofrimentos e eu já me via como uma quase mártir!

Ah! Tristemente me enganei. Nós todos permanecemos em boa saúde - e nenhum dos marinheiros se afogou de exaustão -, o navio não pegou fogo e as provisões não estragaram - apenas continuaram tão ruins como eram antes (PFEIFFER apud EBERSPÄCHER 2020: 125).

O relato não é feito sem alguma ironia: Pfeiffer parece fazer piada com aqueles que, levados por histórias imaginárias e fantasiosas, acreditavam que algo extraordinário se passaria na mudança de hemisfério. Narrativamente, os imaginários mais fantasiosos são colocados nas vozes dos outros passageiros, não na sua própria - estrutura que permite tanto um efeito de distanciamento da autora quanto a essas expectativas, vendo isso apenas na condição de observadora, quanto uma imagem de compartilhamento de crenças entre outros indivíduos. Assegura, assim, sua posição, enquanto narradora, de uma pessoa um tanto mais racional e até científica.

Quando a embarcação já se aproxima das terras brasileiras, os passageiros observam pássaros pelo céu. Depois que alguns são capturados e mostrados no deque do navio, um dos passageiros sugere que um seja morto e empalhado. Pfeiffer, então, descreve brevemente um dos imaginários dos marinheiros, contrários à ideia proposta: “eles disseram que, se pássaros fossem abatidos a bordo do navio, seguiria à morte uma longa calmaria" (PFEIFFER apud EBERSPÄCHER 2020: 127), o que evidentemente prejudicaria a continuidade da jornada marítima. Logo em seguida, a própria autora comenta o acontecido sob a vista dos imaginários: "essa era uma prova de que as superstições ainda têm raízes longas nas mentes dos marinheiros" (PFEIFFER apud EBERSPÄCHER 2020: 127). Novamente a autora se distancia narrativamente do imaginário apresentado por ela na voz de outros, nesse caso, os marinheiros.

Pandaemonium, São Paulo, v. 24, n. 44, set.-dez. 2021, p. 124-140 
EBERSPÄCHER, G. - Imaginários europeus no Brasil Imperial

Outra expectativa dos passageiros do navio em relação à chegada ao Brasil foi, em grande parte, criada pelo próprio capitão. Pfeiffer relata:

Na manhã do dia 17 de setembro, depois de quase dois meses e meio, pisei novamente em terra firme. O capitão nos acompanhou pessoalmente até a terra, depois de ter recomendado enfaticamente a todos não contrabandear nada para dentro do país, muito menos cartas seladas. "Em nenhum outro lugar", assegurou, "a alfândega é tão rigorosa e as multas, tão altas".

Por isso, quando avistamos o navio da guarda costeira, ficamos receosos e achamos que seríamos revistados da cabeça aos pés. O capitão pediu permissão para nos acompanhar até a terra firme. Isso foi logo atendido - e a coisa toda logo foi resolvida. Durante o tempo que ficamos hospedados no navio, indo e voltando da cidade, nunca mais fomos revistados; apenas quando trazíamos malas e caixas conosco tínhamos que passar na alfândega, onde todos os pertences eram revistados com rigor e as mercadorias, livros e etc recebiam altos impostos (PFEIFFER apud EBERSPÄCHER 2020: 130).

Aqui, pode-se observar como um europeu (o capitão do navio) dissemina informação sobre o funcionamento da sociedade brasileira entre seus conterrâneos. Apesar de ser aqui uma informação de cunho prático, e até um alerta de como lidar com a chegada em terra, se observa também a criação de uma imagem de um espaço burocrático, rigoroso e até caro, com uma alfândega fechada e controlada.

Um dos momentos que mais evidenciam o ponto de vista europeu imperialista de Pfeiffer é sua maneira de descrever outros povos e, no caso brasileiro, os negros escravizados e os povos indígenas. Apesar de parecer uma figura vanguardista (uma mulher viajante em um mundo masculino), Pfeiffer está inserida no pensamento de seu tempo e replica várias das estruturas raciais que são base do pensamento de seu tempo. Assim, o adjetivo feio e descrições que ressaltam as diferenças físicas dos outros povos em relação ao europeu (público-alvo do texto de Pfeiffer) são frequentes. A experiência da autora no Brasil é, possivelmente, a primeira vez que ela tem contato com culturas mais distantes da europeia (sua viagem anterior mais longa fora ao Oriente Médio), e Habinger (2014) define sua postura como um choque de cultura. Esse eurocentrismo apresenta também um pensamento abolicionista, em que Pfeiffer defende que os escravizados deveriam ter acesso a uma educação de qualidade - e que uma diferença em termos de conhecimento não se explica por falta de intelecto, mas sim por falta de acesso a uma educação nos mesmos moldes que os europeus. Mas esse é um pensamento que a autora parece desenvolver no Brasil, tendo contato com negros em sociedade. O trecho a seguir pode ser tomado como exemplo da surpresa da autora diante de um grupo de negras com habilidades manuais requintadas, o que quase se opõe à imagem de negros tida na Europa: 
EBERSPÄCHER, G. - Imaginários europeus no Brasil Imperial

No Brasil, todos os tipos de trabalhos pesados e sujos, internos ou externos, são realizados pelos negros, que ocupam, na realidade, o espaço das classes mais baixas. Muitos, porém, aprendem alguns ofícios, e com frequência são comparáveis aos mais talentosos europeus. Vi negros trabalhando na maioria das lojas elegantes, produzindo roupas, sapatos, tapetes e artigos em ouro ou prata; e conheci várias negras com roupas finas produzindo os vestidos mais belos, com bordados delicados. Com frequência achei que estava sonhando, quando contemplei essas pobres criaturas, que eu imaginava que estariam em suas florestas nativas, exercendo tais ocupações em lojas e cômodos! (PFEIFFER 1850: 133134).

Nesse parágrafo fica visível que a realidade brasileira não corresponde completamente à expectativa da autora que é, por sua vez, baseada em crenças tidas pela própria sociedade da qual ela vem. Ela se surpreende com os escravizados e suas capacidades de viver e produzir em sociedade - ao contrário de uma imagem mais similar a "animais selvagens" compartilhada por ela até então. Usando narrativamente uma comparação entre as realidades vistas tanto na Europa como no Brasil e a expectativa que tinha, a autora vê na cena uma semelhança bem maior entre esse "outro" e ela mesma do que ela esperava. Esta percepção inspira alguns dos seus comentários posteriores sobre a capacidade intelectual e o acesso à educação.

Pfeiffer faz ainda outras observações sobre a escravidão, apesar de não explicitar completamente, em seu texto, as leis sobre esse tipo de comércio no Brasil do período mas ainda assim faz descrições pertinentes para a questão. Por exemplo, menciona não ter visto nenhum mercado ou comércio explícito de pessoas - o que provavelmente era verdade, já que esse comércio era repudiado em grande parte do mundo e, portanto, feito muitas vezes longe dos olhares da população em geral, além do tráfico transatlântico já ser proibido desde 1831. Mas também escapa da autora observar que os escravizados nascidos nas fazendas eram posse do fazendeiro (a Lei do Ventre Livre data de 1871). Assim, como leitores da obra quase dois séculos depois de sua publicação original, nos cabe perguntar qual realidade brasileira foi mostrada a Pfeiffer pelos mediadores (em geral, alemães ou austríacos que moravam no Brasil ou ainda guias que traduziam ou mediavam suas conversas), afinal, como uma mulher europeia que visitava o país, muitas informações podem ter sido vetadas a ela, para que ficasse menos impressionada negativamente com a situação - e qual impacto essa mediação pode ter tido sobre sua percepção do país. Como exemplo disso, ela afirma o seguinte sobre a escravidão:

Apesar de tudo, os escravos estão longe de serem tão mal tratados como imaginamos na Europa. No Brasil eles são normalmente bem tratados; não trabalham demais, têm uma alimentação boa e nutritiva e não recebem punições que sejam muito pesadas ou frequentes. [...] Eu realmente duvido que, no todo, a maioria desses escravos sejam pior 
EBERSPÄCHER, G. - Imaginários europeus no Brasil Imperial

tratados do que os servos na Rússia, Polônia e Egito, onde não são chamados de escravos (PFEIFFER 1850: 135).

Sim, é possível pensar que existiam situações piores. Mas será que ela teve, de fato, contato com os aspectos que conhecemos hoje sobre a escravidão? A tortura física e emocional, os abusos com as mulheres, a escravização infantil? Ou será que essa parte da realidade foi vetada a ela, que teve contato apenas com uma camada mais superficial da escravidão, o que a teria levado a fazer a observação acima? Pode-se fazer todas as hipóteses, mas jamais saberemos o que ela de fato soube e acreditou ser "melhor" do que outras situações análogas à escravidão - o que podemos de fato observar é que existia sim uma imagem de que escravos seriam necessariamente mal tratados, ao menos da parte de Pfeiffer, o que é em si um imaginário forte sobre o funcionamento social brasileiro.

\section{$5 \bigcirc$ Brasil como Paraíso na Terra}

Um dos imaginários europeus frequentes sobre o Brasil se refere à descrição da natureza e do espaço físico. A imagem de um Paraíso na Terra foi uma constante em escritos sobre o país desde a época colonial e já foi estudada por outros pesquisadores. Em Visões do Paraíso, livro lançado em 1959, Sérgio Buarque de Holanda estuda como os escritos do descobrimento criaram e mantiveram um mito edênico, ou seja, associam o novo continente ao Jardim do Éden. Para o autor, alguns dos fatores que justificam essa aproximação são a ausência das enfermidades europeias entre os indígenas que mudou com a colonização), a ausência de um mal explícito, a natureza abundante, a nudez dos habitantes e assim por diante. Pelos motivos já apresentados, os relatos de viagem para o Brasil ainda eram um tanto raros - o que fazia com que a imagem de paraíso intocado se perpetuasse.

Como exemplo, segue a descrição de uma floresta feita por Pfeiffer:

A uma légua de Canto Gallo chegamos em uma pequena cachoeira e então continuamos pela floresta mais bonita que já vi. Uma pequena subida na orla de um riacho nos levou até ela. Palmeiras com suas copas altas e majestosas se erguiam sobre as árvores floridas, que estavam tão entrelaçadas que formavam uma espécie de telhado; orquídeas se multiplicavam pelos ramos e galhos; plantas trepadeiras e samambaias subiam pelas árvores, se misturando aos galhos e formando grandes muros de flores com as cores mais bonitas e com o mais doce perfume; delicados beija-flores voavam por todos os lados; acima, os tucanos com suas belas cores voavam timidamente; papagaios e periquitos se equilibravam nos galhos; vários outros pássaros de cores maravilhosas, que eu vira somente no museu, também viviam neste bosque encantado. Parecia que eu estava passeando por um parque de fadas, e achei que a qualquer momento veria silfos e ninfas (PFEIFFER apud EBERSPÄCHER 2020: 167).

Pandaemonium, São Paulo, v. 24, n. 44, set.-dez. 2021, p. 124-140 
EBERSPÄCHER, G. - Imaginários europeus no Brasil Imperial

A descrição feita pela vienense conta com fatores naturais, como os tipos de plantas e animais, até que apresenta um grupo lexical do campo semântico do fantástico ou mitológico. Ao evocar esse campo semântico, a autora afasta a floresta de um campo do natural ou botânico e lhe confere um status onírico que corresponde a um imaginário do Paraíso na Terra. Além disso, a autora usa com frequência adjetivos (que, quando se referem à natureza, tendem a ser "exuberante" e assim por diante). Esse exemplo reforça e concorda com o imaginário de um Paraíso na Terra.

Porém, essa imagem tão presente no imaginário europeu sobre o Brasil composto de natureza começa a mudar com o período colonial e a sociedade que se forma no país, com a criação de plantações e um sistema industrial emergente de açúcar, café e outros produtos. O espaço deixa de ser só natureza para abrigar uma sociedade colonial. Isso também fica evidente na obra de Pfeiffer, quando descreve o espaço social, materializado pelas cidades, colônias e fazendas - ou seja, os espaços manipulados pelo colonizador. Nesse caso, os adjetivos não costumam ser tão positivos assim. Pelo contrário, Pfeiffer critica a simplicidade da arquitetura, o mau funcionamento das cidades, a pobreza constante, a falta de infra-estruturas culturais, etc. Aqui, o espaço é apresentado quase como uma oposição à ideia de paraíso na Terra.

Esse contraste é observado por Flora Süssekind (1990). Em sua pesquisa sobre a origem do narrador na literatura brasileira e a relação que faz entre a produção nacional e a literatura de viagem produzida sobre o país, Süssekind menciona um deslocamento por parte de vários viajantes europeus, que buscam um "Brasil-só-natureza" (SÜSSEKIND 1990: 28) e encontram, na realidade, uma sociedade complexa e cheia de camadas de compreensão. Em outras palavras, o sistema de exploração português e a situação social e econômica que ele acarreta são criticados pelos viajantes, que imputam a eles a corrupção de uma natureza tão exuberante quanto era. Um exemplo disso pode ser observada no texto abaixo, onde esse imaginário de beleza exuberante é contrastado com uma realidade encontrada pela viajante:

Eu ouvira muito na Europa sobre a grandeza e a exuberância da natureza no Brasil, da felicidade do céu sempre limpo, do maravilhoso calor de uma primavera constante. É verdade que a vegetação aqui é tão rica e o crescimento tão poderoso e exuberante, provavelmente mais do que em qualquer outro país do mundo, que qualquer um que queira ver o trabalho da natureza em força total e em atividade contínua deve vir para o Brasil. Ainda assim, não se deve achar que aqui tudo é belo e bom e que não há nada que possa enfraquecer o efeito mágico da primeira impressão (PFEIFFER apud EBERSPÄCHER 2020: 142). 
EBERSPÄCHER, G. - Imaginários europeus no Brasil Imperial

Neste parágrafo, é possível observar a imagem de um Paraíso na Terra sendo contrastada com a realidade colonial. Entre aspectos negativos apresentados ao longo da descrição de Pfeiffer, estão a ausência de construções interessantes, poucas opções culturais na cidade, excesso de moradores de rua e pessoas em situação de pobreza, lixo nas ruas... são vários os aspectos urbanos e culturais que distanciam a autora de uma realidade europeia e são consideradas por ela como traços de uma civilidade menor, o que é narrado com um certo tom de decepção com uma realidade tão problemática que não corresponde completamente à imagem que ela esperava enquanto receptora de um imaginário anterior. Assim, apesar da natureza exuberante, o país deixa a desejar em outros aspectos. O trecho apresentado não só mostra o imaginário de beleza exuberante, mas também o reconstrói para o leitor, indicando que a imagem corresponde apenas parcialmente à realidade.

O céu volta a ser mencionado um pouco mais adiante no livro, desta vez para falar como nuvens são frequentes: "Dias claros e sem nuvens foram tão raros entre os dias 16 de setembro e 9 de dezembro que poderia tê-los contado; e não consigo entender como tantos viajantes falam sobre o céu sempre bonito e azul do Brasil. Isso deve ser verdade em alguma parte do ano" (PFEIFFER 1850: 50). A autora novamente contrapõe a sua percepção do espaço com um imaginário anterior, mas aqui apresenta uma expectativa criada a partir de informações compartilhadas por outros viajantes que vieram ao país antes dela. Percebe-se, assim, a influência que esses textos mais factuais já começam a ter.

A descrição espacial de Pfeiffer conta com um espaço imaginário (aquele que se acreditava que seria encontrado, seja por base em um imaginário compartilhado ou ainda pelos relatos de viajantes que vieram ao país antes dela) e um espaço real, observado e descrito a partir do ponto de vista da própria escritora. A contraposição constante entre os dois em forma de comparação é uma das ferramentas narrativas mais frequentes na construção da descrição espacial no texto de Pfeiffer.

\section{$6 \bigcirc$ imaginário na construção narrativa}

Relatos de viagem são repletos de descrições, sejam de jornadas ou de destinos. Pfeiffer usa adjetivos e advérbios (nem sempre positivos) para construir a maioria das descrições. Mas em muitos momentos ela se utiliza também de uma comparação mais direta entre 
EBERSPÄCHER, G. - Imaginários europeus no Brasil Imperial

seus destinos de viagem e a vida europeia. Os trechos apresentados neste artigo mostram comparações ainda mais específicas: entre um imaginário já estabelecido no lugar de origem da autora com suas descobertas de viagem. Esta é uma ferramenta narrativa relativamente frequente na obra de Pfeiffer e gera alguns efeitos narrativos.

Um deles é a ativação de um conhecimento prévio do leitor ou da leitora. Por mais que a pessoa não tenha tido acesso a livros e outras informações factuais sobre o Brasil daquela época, é provável que tenha "ouvido falar" alguma coisa e compartilhe uma imagem geral, fantasiosa ou não, do que é o país. Ao evocar esse imaginário em seu texto, Pfeiffer se aproxima de seus leitores e incentiva o estabelecimento de um diálogo maior com a obra, considerando o conhecimento prévio e não exigindo a construção de um conhecimento do zero. As comparações entre o imaginário e a realidade fazem com que a imagem que a autora teve do Brasil se construa narrativamente por contraste ou complementação, com algo esperado, conhecido e compartilhado sendo modificado pela narrativa de Pfeiffer. A menção do imaginário já estabelecido é feita principalmente para mudá-lo ou até invertê-lo.

Esse artifício tem também um grande impacto na formação de Pfeiffer como narradora. Ao contrapor constantemente sua percepção com um imaginário já existente, a autora alcança pelo menos dois efeitos possíveis. Em primeiro lugar, se afirma como um par de olhos mais frescos, que podem descrever uma realidade de uma maneira melhor, criando uma oposição capaz de diferenciar e destacar seu trabalho aos olhos dos leitores. Em segundo lugar, ao não negar ou excluir completamente esse imaginário, e sim dialogando constantemente com ele, Pfeiffer consegue um relato mais verossímil e simpático. Se descrevesse apenas uma realidade diferente da esperada, é possível que seu relato fosse simplesmente desacreditado (como viajante mulher, sua reputação e a seriedade de seu trabalho eram frequentemente questionados). Como Süssekind (1990) afirma, o viajante se pretende um narrador confiável - e o estilo de Pfeiffer com frequência converge a isso.

A apresentação desses imaginários ao longo do texto também permite que o leitor de hoje tenha acesso a essa imagem tida do Brasil naquele período e acompanhar, pelos olhos de Pfeiffer, o que se concretiza na realidade por ela encontrada. Ao vir para o Brasil e encarar a realidade com seus próprios olhos, a autora complementa e até contradiz várias crenças anteriores, o que se mostra como uma surpresa tanto para ela quanto para seus leitores. 
EBERSPÄCHER, G. - Imaginários europeus no Brasil Imperial

É necessário também mencionar que, ao narrar suas experiências em espaços estrangeiros, Pfeiffer se torna ela mesma uma fonte para uma recepção e a recriação de um imaginário. Ainda não foram feitos estudos completos sobre sua recepção e sua eventual influência sobre os leitores do seu tempo, mas se sabe que ela se tornou uma bestseller do período (HABINGER 2014). Foi também traduzida rapidamente para o inglês, tendo a obra difundida na Inglaterra - em 1851, a editora Strand já publicava a segunda edição do livro. Considerando que suas experiências no Brasil raramente mencionam indivíduos específicos (e quase todos os mencionados são europeus), dando centralidade para coletivos (portugueses, mulatos, índios, negros...) para descrever costumes sociais, ela acaba, por sua vez, contribuindo com uma estereotipização dos povos descritos, podendo se tornar fonte para a formação de novos imaginários por parte de seus leitores.

\section{Conclusão}

Quando saiu de casa para viajar pela primeira vez, Pfeiffer não tinha certeza do que encontraria - cogitava inclusive que não retornaria viva para casa, tamanha era a incerteza que as jornadas traziam então. Ainda assim, se tornou uma grande viajante, esteve em todos os continentes (com exceção da Antártida) e publicou cinco livros sobre suas aventuras.

Como são raros os comentários biográficos em sua obra, é difícil saber o que motivou suas viagens. Mas se sabe que era uma leitora voraz de relatos de viagem pelos seus esboços biográficos (Biographische Skizze: Ida Pfeiffer, nach ihren eigenen Aufzeichnungen, in PFEIFFER 2017). Sabemos assim que as imagens de outros viajantes sobre o mundo eram de conhecimento de Pfeiffer e provavelmente alimentaram suas expectativas quanto às suas próprias viagens. E isso é, em parte, o que seu texto revela: uma viajante com expectativas prévias do lugar que encontraria. Mas o texto de Pfeiffer mostra mais que isso. Mostra também uma autora ciente do imaginário que antecede sua leitura do mundo e que o usa em sua narrativa para construir imagens novas. Uma autora que busca um diálogo com seu leitor, além de por como uma voz crítica que questiona os conhecimentos anteriores com base na sua própria experiência e observação, se aproximando de um discurso mais científico. 
EBERSPÄCHER, G. - Imaginários europeus no Brasil Imperial

Para além de seu texto, esses trechos apresentam também a imagem do Brasil Imperial em outros países, constituindo um documento histórico importante para os mecanismos imperialistas presentes nas narrativas do período.

\section{Referências bibliográficas}

EBERSPÄCHER, Gisele. Ida Pfeiffer e o Brasil: Literatura de viagem e sua tradução como Bildung. Dissertação (Mestrado em Letras) - Setor de Ciências Humanas, Universidade Federal do Paraná, Curitiba, 2020.

FRANÇA, Jean Marcel Carvalho (org). Mulheres viajantes no Brasil: antologia de textos de Jemima Kindersley, Elizabeth Macquarie, Rose Freycinet. Rio de Janeiro: José Olympio, 2008.

GRAHAM, Maria. Journal of a Voyage to Brazil, and residence there, during part of the years 1821, 1822, 1823. Londres: Longman; Hurst; Rees; Orme; Brown; Green, 1824.

HABINGER, Gabriele. Eine Wiener Biedermeierdame erobert die Welt: Die Lebensgeschichte der Ida Pfeiffer. Viena: Promedia Verlag, 2014.

Holanda, Sérgio Buarque de. Visão do Paraíso: os motivos edênicos no descobrimento e colonização do Brasil. São Paulo: Brasiliense; Publifolha, 2000.

PfEIFFER, Ida. Eine Fraufahrt um die Welt. Reise von Wien nach Brasilien, Chili, Otahaiti, China, Ost-Indien, Persien und Aleinasten. Viena: Verlag von Carl Herold, 1850.

PfEIFFER, Ida. Ida Pfeiffer: Ausgewählte Werke. Musaicum Books, 2017. Edição do Kindle.

PRATT, Mary-Louise. Imperial Eyes: travel writing and transculturation. 3 ed. Londres: Routledge, 2003.

SERRANO, Sónia. Mulheres Viajantes. Lisboa: Tinta da China, 2017.

SOLNIT, Rebecca. A história do caminhar. Tradução de Maria do Carmo Zanini. São Paulo: Martins Fontes, 2016.

SÜSSEKING, Flora. O Brasil não é longe daqui. São Paulo: Companhia das Letras, 1990.

Recebido em 30 de dezembro de 2020 Aceito em 22 de fevereiro de 2021 